\title{
O papel do Itamaraty na definição da política externa do governo Collor de Mello
}

\author{
The role of Itamaraty in the foreign policymaking \\ of the Collor de Mello administration
}

GUILHERME STOLLE PAIXÃO E CASARÕES*

Rev. Bras. Polít. Int. 55 (1): 135-153 [2012]

O objetivo deste trabalho é investigar o papel do Itamaraty na formulação da política externa do governo Collor, relação comumente observada como frágil, em função do grande voluntarismo político atribuído ao presidente da República (Batista 1993). Busca-se responder a uma pergunta relativamente simples, mas aparentemente controversa nesse caso: o Ministério das Relaçōes Exteriores pôde exercer seu protagonismo no tocante à política externa brasileira (PEB) entre 1990 e 1992? A julgar pela "impressão geral" que se tem sobre o papel do Itamaraty, sim. Afinal, ao menos até a conclusão de nossa transição democrática, um dos mais aventados "pontos pacíficos" da literatura referia-se ao expressivo controle, por parte do Itamaraty, sobre a condução e, na maioria das vezes, também sobre a formulação de nossa política exterior (Cheibub 1985) ${ }^{1}$.

Falar do protagonismo do Itamaraty, por outro lado, é contraintuitivo - considerando que a literatura existente sobre o assunto aponta que o serviço diplomático foi marginalizado do processo decisório da PEB de Collor, sobretudo no que se refere à sua formulação (Batista 1993; Lima 1994; Hirst e Pinheiro 1995; Vigevani e Cepaluni 2011). Devemos, antes de tudo, enfrentar dois mitos que foram erguidos naquele contexto. O primeiro deles é o de que o corpo diplomático brasileiro não teve voz nem vez nas determinaçôes da inserção internacional do Brasil entre 1990 e 1992. O segundo, intimamente ligado ao anterior, é o de

\footnotetext{
* Mestre e doutorando em Ciência Política pela Universidade de São Paulo (USP), Mestre em Relações Internacionais pela Universidade Estadual de Campinas (Programa San Tiago Dantas/Unicamp), Professor de Relaçōes Internacionais das Faculdades Integradas Rio Branco, Fundação Armando Alvares Penteado (FAAP) e Fundação Getulio Vargas (FGV) (casaroes@gmail.com).

1 Essa percepção foi matizada em estudos recentes, no tocante ao período pós-Guerra Fria - sobretudo a partir do governo Fernando Henrique Cardoso (1995-2002) -, nos quais o papel da diplomacia presidencial (Danese 1999; Cason e Power 2009), das demais burocracias do Executivo (Sanchez-Badin e França 2010), dos partidos políticos (Oliveira e Onuki 2010), do poder Legislativo (Lima e Santos 2001) e da opinião pública (Faria 2008) ganhou novos contornos e, naturalmente, despertou interesse acadêmico.
} 
que o americanismo que caracteriza a política externa daquele governo é função única e exclusiva do presidente da República e de sua concepção muito particular sobre o papel dos Estados Unidos ao fim da Guerra Fria. Buscaremos lidar com essas duas questôes, tentando encontrar seus fundamentos, inconsistências lógicas e dificuldades empíricas. Pretende-se, ao fim e ao cabo, jogar nova luz sobre a relação Estado-diplomacia sob o breve mandato de Fernando Collor de Mello, mais complexa e nuançada do que sugere o já evocado "consenso" da literatura.

Este texto será dividido em três partes, que buscarão responder a diferentes questóes acerca das relações entre Itamaraty e o presidente da República. Na primeira delas, a pergunta-chave é a seguinte: é possível, no caso brasileiro, pensar a política externa desvencilhada da atuação do Ministério das Relações Exteriores? Parte-se da hipótese de que, tendo em mente a noção de insulamento burocrático e a tradição institucional do Itamaraty, remover o corpo diplomático das decisōes de política externa é inviável e incompatível com o papel histórico por ele exercido como centro de gravidade da política externa.

Não obstante, pode-se alegar que o governo Collor representou algum grau de ruptura, que deve ser investigado. Como compreender uma "guinada" como aquela que se observou na política externa brasileira, ao fim da Guerra Fria? $\mathrm{Na}$ segunda seção deste texto, busca-se compreender as transformações da inserção brasileira à luz das disputas e das dissonâncias dentro do corpo diplomático. Nesse contexto, as escolhas do presidente Collor, seja em termos dos personagens que encabeçaram a condução de sua política externa, seja no tocante aos formatos institucionais que o Ministério das Relações Exteriores assumiu, diante de um conjunto de reformas, serão colocadas em questão.

A terceira parte ataca a dimensão conceitual da política externa brasileira, buscando subsídios para compreender a inflexão observada com o governo Collor, bem como para qualificá-la. Não sendo possível remover os vínculos entre o Itamaraty e a PEB, se houve algum tipo de mudança paradigmática, ela tem que ser compreendida no contexto dos mapas cognitivos disponiveis ao corpo diplomático. Defende-se a ideia de que, ao contrário das análises que situam a política externa de Collor no extremo americanista do pêndulo paradigmático² (Batista 1993; Lima 1994), houve uma espécie de americanismo mitigado, quer dizer, uma inserção que zela pela autonomia do Brasil frente ao sistema internacional, mas cujo raio de ação está limitado pelos constrangimentos impostos tanto pelas transformações estruturais em marcha, quanto pelas novas circunstâncias domésticas - que, naturalmente, ressoam também sobre a diplomacia, embora com muito mais vagar.

2 Diversos autores do campo da Política Externa Brasileira situam a inserção do Brasil numa lógica pendular, encontrando-se, num de seus extremos, o alinhamento incondicional aos Estados Unidos (o chamado americanismo) e, no outro, a busca pela total autonomia externa, não alinhada aos interesses norte-americanos (o chamado universalismo ou globalismo) (Lima 1994; Mello e Silva 1995). 


\section{Política externa sem o Itamaraty?}

Busca-se, antes de qualquer outra coisa, enfrentar o argumento do embaixador Paulo Nogueira Batista, segundo o qual o Itamaraty "não participou ativamente da formulação da política externa de Collor nem foi tampouco o seu principal executor. Naquilo que lhe coube executar, teve, porém, graças ao profissionalismo de seus quadros, atuação minimizadora do custo de algumas posturas presidenciais" (Batista 1993, 123).

$\mathrm{O}$ argumento, da forma como foi colocado, parece polarizar uma chancelaria altamente profissional a um presidente amador, inconsequente ou voluntarista a cargo da política externa. Além disso, conduz o MRE às margens do processo decisório sobre a inserção internacional brasileira daquele período. Isso seria possível, num contexto como o brasileiro, no qual o Itamaraty tradicionalmente gozou de ampla autonomia sobre a determinação dos rumos da política exterior?

Defende-se a ideia de que a chancelaria se manteve central nas determinações da política externa por duas razões: em primeiro lugar, porque não há muitos meios, sobretudo num contexto democrático, para alijar uma burocracia do processo decisório. Isso se torna particularmente difícil no caso da política externa, cuja burocracia responsável por sua formulação e implementação passou por um formidável processo de insulamento burocrático (Cheibub 1985). Em segundo lugar, porque os rumos desejados pelo governo Collor não eram, em princípio, incompatíveis com as linhas-mestras que orientavam, historicamente, nossa inserção internacional. Mais que isso: olhando-se em retrospectiva, algumas das posições frequentemente atribuídas ao presidente Collor, como a abertura econômica, não eram exatamente novas no contexto do MRE, embora tenham sido impulsionadas pelo novo governo.

A respeito da convergência (mesmo imperfeita) entre os interesses de Collor e as expectativas do Itamaraty, sustenta Velasco e Cruz (2004) que, não obstante o "selo" de Collor que marca a abertura neoliberal de sua política externa, a ele não pode ser atribuída a concepção das transformações em seu sentido lato. De fato, parece-nos implausível supor que o presidente tenha construído todo um conjunto de diretrizes para a inserção internacional do Brasil, a partir de um marco neoliberal, que fora simplesmente replicado pelos diplomatas que gravitavam ao seu redor. A paternidade atribuída a Collor é certamente exagerada, de um lado, quando se toca no assunto da liberalização econômica; as transformações da PEB no período, por outro lado, também são dramatizadas, e muitas vezes se esquece de que os princípios básicos da inserção internacional brasileira foram todos respeitados e levados a cabo pela chancelaria, não tendo o governo Collor sido nenhuma exceção nesse sentido.

A abertura econômica, que muitos atribuirão às vontades neoliberais de Collor vis-à-vis o nacionalismo do nosso serviço diplomático, já vinha sendo discutida (de diferentes maneiras) no Itamaraty, e muitas das reformas nesse sentido, ainda 
no governo Sarney, foram encampadas pela chancelaria. Lembremo-nos de que, no auge do contencioso da informática, era justamente o MRE que funcionava como o contrapeso dos setores mais fortemente protecionistas, buscando uma agenda positiva com os Estados Unidos. A liberalização comercial, embora levada às vias de fato no governo Collor, já havia sido gestada na esfera da Comissão de Política Aduaneira desde 1985, quando começou a se estudar a revisão das Tarifas Aduaneiras Brasileiras (Velasco e Cruz 2004, 143). As posições, portanto, não eram novas, mas talvez estivessem esperando o tempo certo para virem à tona, tendo em mente a lógica e os compromissos possíveis no contexto do Estado desenvolvimentista.

Uma demonstração ainda mais evidente de que as transformações empreendidas no governo Collor não eram inéditas pode ser encontrada na postura do primeiro chanceler de Sarney, Olavo Setúbal. Ele buscou, durante sua curta gestão à frente do MRE, romper com o paradigma universalista que prevalecia no Itamaraty. Mesmo que não tenha logrado êxito, frente à resistência da corporação diplomática, o argumento evocado pelo chanceler muito se assemelha com aquele apregoado por Fernando Collor meia década mais tarde. Nas palavras de Vizentini (2003, 66), Setúbal alegava "que o Brasil era um país Ocidental, que deveria maximizar suas oportunidades individuais, em cooperação com os EUA, para chegar ao Primeiro Mundo".

A despeito do insucesso inicial de Setúbal (explicada, em parte, pela recalcitrância do Itamaraty em abandonar uma posição terceiro-mundista que, em geral, havia sido exitosa), a própria chancelaria deslocou, aos poucos, sua retórica para o campo liberal ao final do governo Sarney. Isso se deu, sobretudo, pela voz do secretário-geral de Política Exterior do MRE, Paulo Tarso Flecha de Lima - que já argumentava, nos idos de 1988, que "[a] continuidade do dinamismo do nosso processo de desenvolvimento exige uma política coerente e gradual de liberalização de importaçôes" (Flecha de Lima, 1988, 101, grifo nosso). Prossegue o embaixador:

A modernização de nossa economia é certamente o caminho para uma inserção mais construtiva e moderna do Brasil na economia internacional. É também o corolário natural da sociedade democrática que desejamos consolidar e na qual não seria possível conciliar a hipertrofia do Estado com a desejável liberdade de ação e de iniciativa (idem, 105).

A julgar pelas colocações de Flecha de Lima, pode-se perceber que havia certo flerte com posições mais liberais, em especial nas questôes econômicas e nas relaçôes entre Brasil-EUA. Essas posições foram gestadas, como observado, desde o início da transição democrática, e não após a chegada de Collor no governo, interpretação dominante na literatura. Devidamente amparadas pelos segmentos sociais politicamente relevantes, elas permitiram que de dentro do Itamaraty também se operasse uma mudança, cuja expressão mais visível foi a guinada de orientação internacional observada com a chegada de Fernando Collor ao poder. 
$\mathrm{O}$ respeito às tradiçôes da inserção internacional brasileira, por outro lado, manteve-se em suas linhas gerais no governo Collor, ao contrário do que sugere Batista (1993). O primado do direito, que baliza nossa inserção internacional desde tempos imemoriais, serviu de fio condutor àquela política externa, como bem nota seu primeiro operador, o então chanceler Francisco Rezek: "[o primado do direito] nos caracteriza e nos distingue (...). Eu assumo a chancelaria do governo Collor, tendo como diretriz dele apenas a fidelidade àquilo que havia de melhor na nossa politica externa e à abertura" (Rezek 2011, grifo nosso).

Talvez o ministro tenha se esquecido de um momento controverso de nossa participação internacional - possivelmente o único -, a invasão norte-americana à República Dominicana, a qual o Brasil não somente apoiou, como dela participou ativamente. Isso talvez só confirme o fato de que, sob Castello Branco, se adotou uma política externa excepcional no que concerne às tradiçōes brasileiras. Não foi, certamente, o caso do governo Collor. Os dois episódios que potencialmente corresponderiam à invasão dominicana de 1965 - o auxílio brasileiro na invasão do Panamá, em 1989, e sobretudo o envio de tropas nacionais à Guerra do Golfo, em 1990 - simplesmente não ocorreram, o que sugere, ao menos no discurso oficial, que o Brasil não estava disposto a abandonar os princípios de sua política externa no afã de melhorar as relaçôes com os EUA. Não deixa de ser interessante notar que, desde a eleição de Collor, o próprio presidente fez questão de repudiar, em nome dos princípios da $\mathrm{PEB}$, o envolvimento brasileiro nas questóes militares norte-americanas. A primeira delas foi a resposta dada por Fernando Collor, então presidente-eleito, em entrevista no National Press Club aos 26 de janeiro de 1990, a um jornalista que lhe havia perguntado se a questão do Panamá interferiria nas relações bilaterais entre os dois países: "Não há nenhum tipo de empecilho maior no futuro das nossas relações. O governo, não somente o governo americano como o governo das nações com as quais nós temos relaçôes sabem da posição do Brasil de defender (...) a política de não intervenção" ${ }^{3}$

O próprio ex-presidente lembra-se dessa passagem, destacando que seu posicionamento poderia ter conduzido a uma frustração do diálogo com o presidente George Bush, com quem teria uma audiência no dia seguinte:

Nesse momento nós saímos da entrevista, o ministro Marcílio Marques Moreira, que era o nosso embaixador em Washington, e o ministro Rezek, que seria o meu futuro ministro das Relaçôes Exteriores, estavam apreensivos em função desta resposta e dizendo que em função disto, talvez o presidente Bush cancelasse a audiência. Ele não cancelou, no dia seguinte nós tivemos [a audiência], entramos no gabinete oval e o presidente Bush chegou muito efusivo, me chamando pelo primeiro nome (...). Aí começou a dizer: "olha, sobre a sua entrevista ontem, eu queria explicar essa questão do Panamá...”

3 Transcrito do vídeo original da entrevista, disponível em <http://www.c-spanvideo.org/program/USBr>. Acesso em 17 de agosto de 2011. Grifo nosso. 
(...). Eu disse: "Presidente, olha, eu quero dizer uma coisa, não há a menor possibilidade do meu governo apoiar qualquer ação armada dos Estados Unidos, em qualquer parte do mundo, seja a que pretexto for". (Collor de Mello 2011, grifo nosso)

O teor da conversa parece ter se repetido algum tempo mais tarde, por ocasião da eclosão da Guerra do Golfo, em agosto de 1990. Diante de nova convocação da participação brasileira, o presidente Collor teria sido novamente taxativo com seu contraparte norte-americano, evocando, mais uma vez, o corolário da não intervenção:

Aí veio a guerra do Golfo em 90, ele ligou pra mim, acho que acabou esquecendo ou fazendo de conta que não se lembrava da nossa conversa, pedindo pra que eu mandasse navios ou armas e gente, pessoal militar lá, pra ajudar na coalizão (...) e eu disse: "Presidente, o Sr. se lembra daquela nossa conversa (...)? Não posso fazer nada, nenhum homem eu mandarei”. (Collor de Mello 2011)

Os exemplos dados aqui certamente não esgotam o argumento da convergência "programática" entre o presidente e o Itamaraty, que sustentam nossa tese de que não houve marginalização da chancelaria durante o governo Collor. Talvez a circunstância mais contundente que demonstre o papel do MRE em nossa política externa do período seja a questão da integração regional, sobre a qual já falamos, com outros enfoques. O Mercosul, como se sabe, não foi concebido naquele governo, tendo sido fruto de discussões iniciadas em meados da década de 1980, sobretudo entre os presidentes José Sarney e Raul Alfonsín. Não se tratava, contudo, de mera química pessoal: havia, por trás da iniciativa, um considerável esforço por parte da diplomacia brasileira em tornar o Cone Sul seu eixo prioritário. E foi justamente no governo Collor que se transformou em realidade aquilo que era, até o fim da década anterior, um conjunto de ideias e vontades - não por iniciativa do presidente, mas por articulação de nossa "máquina diplomática e econômica”, como dirá Rezek:

O Mercosul (...) era um processo que já fermentava na chancelaria brasileira, em acordo com as demais [chancelarias, de Argentina, Uruguai e Paraguai], e quando, enfim, Collor tomou posse, tínhamos todos [os presidentes] muito empenhados nisso (...) Vamos por aí e vamos depressa. E realmente foi depressa (...). E não há, na realidade, uma queixa retrospectiva da experiência que foi a fundação do Mercosul (Rezek 2011).

Se o Mercosul fosse a única alternativa de integração econômica diante do Brasil, seria até compreensível insistir em sua consecução, mesmo que não fosse um objetivo particular do presidente da República. Entretanto, havia uma solução paralela, que vinha sendo negociada pelo governo Bush desde junho de 1990, 
a Iniciativa para as Américas. Como bem lembra Velloso (1991), o projeto apelidado de "Plano Bush" - tencionava inaugurar um novo momento das relações entre os Estados Unidos e a América Latina. Parecia claro, naquele contexto, que o governo Bush desejava redefinir a agenda norte-americana para o hemisfério, outrora pautada por consideraçóes excessivamente estratégicas e que levou aquele país a adotar, durante os anos 1980, "uma política em que $90 \%$ do seu tempo, recursos e atenção são dedicados a $10 \%$ da região, i.e., à América Central" (Velloso 1991, 8).

Ora, se a política externa de Collor de Mello nada mais seria "do que a aplicação ao caso brasileiro da filosofia ultraliberal consolidada no chamado Washington Consensus" (Batista 1993, 195), por que o presidente, diante de uma alternativa oferecida pelos Estados Unidos, insistiria no Mercosul? O próprio embaixador Paulo Nogueira Batista oferece a resposta, sugerindo que "andou bem Collor em ouvir o Itamarati [sic] e não aceitar discutir a idéia de Bush de eventual formação de uma Área Hemisférica de Livre Comércio, de contornos mal definidos" (idem, 198-9).

Como é possível governar sem o Itamaraty, submetendo-se ao Consenso de Washington e, ao mesmo tempo, ouvir a diplomacia brasileira? O paradoxo está no fato de que, na visão daquele embaixador, a abertura econômica era sinônimo de alinhamento automático com os EUA e consequente perda de soberania - sendo, portanto, incompatível com os objetivos da política externa. Nada mais distante da realidade. Abrir-se economicamente, imperativo identificado pelo próprio Itamaraty alguns anos antes, era fundamental para que o Brasil pudesse fazer parte de uma nova ordem emergente, em que os objetivos militares eram progressivamente substituídos pelas questões econômicas. A expectativa de nossa política externa, no tocante à abertura, era redimir - como bem nota Rezek - "aquilo que ainda restava de negativo na imagem brasileira [perante o mundo]: o fechamento (...), o hermetismo" (Rezek 2011). A rigor, como se afirmou anteriormente, abertura econômica não seria incompatível com a política externa já existente.

Mas não eram todos os diplomatas a pensar da mesma maneira: os debates em torno da liberalização como prática e do liberalismo como ideologia também tiveram lugar no Itamaraty, e contribuíram para determinados avanços (e tantos outros retrocessos) na formulação da política externa do período.

\section{As dissonâncias da política externa brasileira: liberais versus nacionalistas no MRE}

Como vimos na seção anterior, não se deve subscrever à noção de que o Itamaraty desempenhou um papel "residual" na formulação da política externa do período, em contraste com uma intensa (e errática) diplomacia presidencial. Grande parte dessa interpretação deve-se à lógica de que (1) houve mudanças significativas 
na política externa do período; (2) se houve mudanças, elas não podem ter sido gestadas dentro da chancelaria; e (3) se não vieram da diplomacia, a "paternidade intelectual" das mudanças pertence ao próprio presidente.

Muito embora a personalidade do presidente atue, mesmo que de maneira esparsa, como uma espécie de calibragem ao serviço diplomático na constituição das diretrizes de política externa, estamos falando de uma instituição cujo insulamento é característica definidora, e na qual mudanças ocorrem, por via de regra, de forma gradual. Valendo-se de uma metáfora sugerida por Allison (1969), é como se o presidente da República, na condição de chefe de Estado, fosse uma espécie de quarterback do futebol americano, detentor de um leque de jogadas previamente estabelecidas, chamando uma delas de acordo com a estratégia daquele embate específico ${ }^{4}$. O serviço diplomático seria o restante do time, agindo não de acordo com as vontades pessoais do quarterback ou de cada um de seus membros, mas seguindo roteiros fechados, repertórios pré-estabelecidos, escolhidos em função das circunstâncias e da interpretação dada a um determinado problema.

Essa analogia resolve, em parte, o problema contrafactual colocado sempre que se alega, como foi no caso da política externa do governo Collor, que as mudanças de orientação internacional de um país ocorrem em função de um choque estrutural: se outro presidente fosse eleito no lugar de Collor, os rumos da política externa teriam sido os mesmos? Tudo indica que não, uma vez que as mudanças são fruto de transformações que se sobrepõem nos planos sistêmico/estrutural, doméstico e burocrático. Por isso mesmo, não atribuímos à política externa de Collor uma relação deterministica com os movimentos tectônicos causados pelo fim da Guerra Fria. A aproximação do Primeiro Mundo foi uma saída possivel dentro de um conjunto mais amplo de jogadas, que poderiam incluir uma obstinada manutenção das linhas comerciais com o Terceiro Mundo, ou até mesmo uma inflexão na direção das nações socialistas, cada vez mais frágeis. Isso não quer dizer, entretanto, que a alternativa primeiro-mundista - que qualificaremos em breve - estivesse fora das possibilidades: ela simplesmente foi aquela da qual o presidente lançou mão, diante daquilo que interpretava como a melhor "jogada".

Se o binômio liberalização econômica/reconstrução de uma agenda positiva com o Primeiro Mundo (sobretudo com os Estados Unidos) constava no rol de possibilidades de uma burocracia que define suas próprias possibilidades de jogo, o que levou insiders como Paulo Nogueira Batista a apontar essa distância intransponível entre Collor e o Itamaraty?

\footnotetext{
4 "De forma a executar rotinas complexas, o comportamento de um grande número de indivíduos deve ser coordenado. A coordenação requer procedimentos operacionais-padrão: regras de acordo com as quais as coisas são feitas. A capacidade garantida para a execução confiável de uma ação que depende do comportamento de centenas de pessoas requer 'programas' estabelecidos. De fato, se os onze membros de um time de futebol [americano] devem atuar adequadamente em uma jogada particular, cada jogador não deve 'fazer o que ele acha que deve ser feito' ou 'fazer o que o quarterback ordena'. Pelo contrário, cada jogador deve realizar as manobras especificadas por uma jogada previamente estabelecida que o quarterback simplesmente chamou naquela situação" (Allison 1969, 698, tradução livre).
} 
Defende-se aqui a suposição - e trata-se, importante frisar, de absoluta especulação - de que parte das acusações realizadas pelo embaixador Batista (e por acadêmicos que, à época, o acompanharam nos argumentos) ao governo Collor, se não foram pessoais, ao menos refletem a distância considerável que separa suas visões de mundo acerca do papel internacional do Brasil. As duas áreas principais das quais Paulo Nogueira Batista se ocupou, ao longo de sua vida diplomática, foram a questão nuclear e o comércio internacional, alinhando-se com veemência à retórica universalista do pragmatismo responsável. Suas ideias nesse campo nos interessam em dois aspectos. Contrastavam, de um lado, com as visões de mundo esposadas pelo próprio presidente Collor. O interesse deste em aproximar-se do Primeiro Mundo, sobretudo o privilégio dado aos Estados Unidos, era visto por Batista como uma "ilusão de ótica", ou até mesmo um "deslumbramento" (Batista 1993). Da mesma maneira, a postura de Collor a respeito da questão nuclear desagradava aos militares, com os quais o embaixador se identificava. A emblemática fotografia na qual o presidente, em 7 de setembro de 1990, joga uma pá de cal (no sentido literal) no poço destinado a testes nucleares, na Serra do Cachimbo, $\mathrm{PA}$, foi encarada como uma afronta não somente à autonomia castrense, como também à independência da política externa brasileira.

Por fim, os chamados "novos temas", como o meio ambiente e os direitos humanos, também podem ter se configurado como ponto controverso entre o embaixador e o presidente. Nota um diplomata próximo do governo Collor que, em contraste à habitual rejeição do governo brasileiro às organizações não governamentais - sobretudo as ambientalistas, tidas como "instrumentos das potências" -, o novo presidente criou um canal pessoal de interação com os movimentos sociais transnacionais. Recebeu pessoalmente, por exemplo, o presidente da Anistia Internacional - que era, até então, "recebido pelo terceiro escalão do Itamaraty"

Também nos interessam as ideias de Paulo Nogueira Batista no sentido de jogarmos luz nas distintas orientaçōes ideológicas que animavam (e dividiam) o serviço diplomático. Tomaremos a imagem descrita por Velasco e Cruz (2004), que retrata um Itamaraty cindido ao meio, face à emergência de grupos mais liberais dentre os quadros de nossa política exterior. Trata-se de uma percepção controversa, uma vez que os diplomatas, em geral, e até mesmo as análises acadêmicas mais tradicionais descrevem o Ministério das Relações Exteriores como um bloco monolítico de interesses. O embaixador Flecha de Lima, contudo, é capaz de identificar dois agrupamentos distintos, aos quais ele chama de liberais, no qual ele próprio se inclui, e nacionalistas, "o grupo do Paulo Nogueira Batista" (Flecha de Lima 2011).

Durante o governo Figueiredo, como vimos anteriormente, o grupo liberal era representado por Roberto Campos, umas das poucas vozes dissonantes dentro

5 Em entrevista concedida ao autor, Brasília, 19 de maio de 2011. O entrevistado pediu para não ser citado diretamente. 
de um amplo consenso nacionalista que sustentava a política externa brasileira (Ferreira 2009). Nos anos Sarney, deve-se fazer uma apreciação mais nuançada: indicações como Olavo Setúbal para a chancelaria, embora não fosse da "Casa", e Paulo Tarso Flecha de Lima como o "homem forte" do Itamaraty, diante da Secretaria-Geral, indicavam uma inflexão liberal, muito provavelmente articulada por Tancredo Neves ${ }^{6}$. Sem o direcionamento político daquele presidente, entretanto, o governo de José Sarney acabou se atendo, até mesmo pelas circunstâncias partidárias, ao pacto nacional-desenvolvimentista, dando continuidade à orientação universalista da política externa brasileira - em respeito, inclusive, aos militares.

Nesse contexto, no qual Paulo Tarso acabou assumindo a posição de chanceler de facto - isto é, responsável pela formulação das grandes posições do ministério -, coube a ele resguardar a unidade do Itamaraty em tempos adversos para a PEB. Assim, mesmo que as visões públicas advogadas pelo secretário-geral expressassem essa orientação liberal, as linhas gerais da inserção brasileira passavam por um processo de aprendizagem lenta, que demandaria uma espécie de catalisador político para se concretizar. As pressōes estruturais, exercidas principalmente pelos Estados Unidos sobre as atitudes mais protecionistas do Brasil, não foram capazes de, por si próprias, causar uma ruptura.

Pode-se dizer que esse impulso político foi dado pela eleição de Collor, em 1989. Mesmo que o presidente não tenha sido responsável per se pela inflexão na política externa brasileira, suas intervenções na estrutura do Ministério das Relações Exteriores, nos limites daquilo que lhe cabia fazer, foram cruciais para os contornos que a orientação brasileira assumiu no advento da nova ordem mundial. Em primeiro lugar, as posiçôes defendidas por Collor ao longo do processo eleitoral, e mesmo na condição de presidente eleito, acabaram criando focos de resistência às mudanças no cerne do MRE. Tomemos, a título de exemplo, a explanação de Marcílio Marques Moreira acerca das resistências apresentadas pelo Itamaraty face à liberalização econômica idealizada ainda no governo Sarney e, mais especificamente, às transformaçôes desejadas por Collor: "[Vários] diplomatas, sobretudo no escalão intermediário, (...) defendiam o status quo ou mudanças muito graduais. $\mathrm{O}$ problema não eram as pessoas em si, muitos deles brilhantes diplomatas, era a cultura do Itamaraty, ainda impregnada pela herança dos barbudinhos" (Moreira 2001, 234, grifo nosso).

O próprio tratamento oferecido por Moreira, diplomata de carreira, à cultura universalista do Ministério das Relaçôes Exteriores - colocada em termos bastante próprios da Guerra Fria - indica a existência de uma trincheira entre o pensamento liberal, difundido entre alguns diplomatas, e os ideais nacional-desenvolvimentistas

6 Refletida, entre outras coisas, numa renovada relação de proximidade com os Estados Unidos, conforme sugerem relatos do embaixador Rubens Ricupero, que assessorou o presidente-eleito em sua viagem oficial (Ricupero 2009), bem como as análises de Silva e Delgado (1985) e Lafer (1985). 
advogados pelo grupo predominante na chancelaria. Mesmo que esse tipo de divisão não seja particular ao governo Collor, a diferença, nesse caso, é que a polarização teria sido induzida pelo presidente, e não fruto de clivagens mais amplas, como era, nos anos 1950, a querela entre nacionalistas e "entreguistas" no tocante aos rumos do desenvolvimento brasileiro.

Em linhas gerais, a referida alegação sustenta-se no argumento de que Collor exerceu seu poder presidencial de forma excessivamente personalista. Isso surtiria, em todos os âmbitos das políticas públicas, o duplo efeito da concentração de poder num só polo decisório e da marginalização dos espaços tradicionalmente responsáveis pela formulação política, independentemente de seu grau de insulamento.

Se tais características são verdadeiras para entendermos, por exemplo, a indicação da detentora da pasta da Economia, Zélia Cardoso de Mello, que constituiu sua esfera de atuação sob o olhar vigilante do presidente, a mesma regra não parece se aplicar plenamente ao Ministério das Relaçôes Exteriores. A indicação de Francisco Rezek veio, conforme lembra o próprio ex-chanceler, como uma espécie de apelo a figuras de relativa expressão em suas respectivas áreas ${ }^{7}$, "que ele não conhecia, tinha visto de longe", diante da ausência de uma equipe constituída previamente (Rezek 2011). Parece sensato, portanto, supor que as relações exteriores foram uma das poucas áreas do Executivo que Collor não buscou monopolizar quando da formação de seu governo, e a indicação de alguém de fora da corporação não sinaliza qualquer intenção no sentido contrário (Lafer 1993).

Por outro lado, o presidente buscou selecionar, dentre os quadros superiores do corpo diplomático, aqueles cuja trajetória e concepçōes de mundo estivessem afinadas a um projeto nacional liberalizante. Essa visão está presente nas constatações de Sebastião Velasco e Cruz, para quem o Itamaraty não foi marginalizado, nem obrigado a absorver uma linha exógena de atuação. O que Collor fez, segundo o autor, "foi intervir no campo fortemente polarizado da diplomacia, consagrando a vitória do lado que advogava políticas compatíveis com o discurso já predominante nas elites brasileiras e com a tônica geral de seu programa de governo" (Velasco e Cruz 2004, 150).

Em avaliação semelhante, e ratificando o que foi exposto acima, Marcílio Marques Moreira aponta as mudanças ocorridas no alto escalão do governo com a chegada de Collor ao poder, em particular no Itamaraty:

Pouco depois da posse [de Collor], me telefonou o novo ministro do Exterior, Francisco Rezek, dizendo que o presidente queria que eu ficasse. E ficaram muito poucas pessoas, como é sabido (...). Até nas embaixadas, onde estavam geralmente embaixadores de carreira, o presidente mudou vários. Durante

7 Como foi o caso de José Goldemberg para a Secretaria de Ciência e Tecnologia, José Lutzenberger para o Meio Ambiente e o próprio Rezek no MRE. 
a viagem de janeiro [de 1990 ao exterior, antes da posse], não gostou de alguns e depois trocou: em Nova Iorque, em Lisboa... Foi uma alteração muito profunda (Moreira 2001, 230).

Ressalte-se que a tentativa de fortalecer a face liberal de um Itamaraty dividido e não miná-lo por fora, como sugerem os críticos - sinaliza que a instituição gozava de prestígio junto ao presidente. "A eficiência da corporação diplomática foi frequentemente mencionada por Collor, e diversos diplomatas foram nomeados em outros ministérios e na assessoria da presidência", como sugere, ainda que discretamente, a observação de Mello (2000, 97, nota 14). Tanto é que a figura mais próxima do presidente-eleito durante o período de transição de governo foi um diplomata de carreira, Marcos Coimbra, que também era seu cunhado - casado com a irmã do presidente, Leda Collor. Ele se transformaria em chefe de gabinete e assessor diplomático do novo chefe de Estado, assumindo um papel central nas determinações organizacionais da política externa.

Esse argumento ganha força frente a uma análise mais detida sobre a composição do quadro mais amplo da política externa de Collor em sua primeira fase (ou seja, entre a posse e meados de 1992, quando Celso Lafer sucede Rezek no contexto de uma profunda mudança ministerial). Em primeiro lugar, há duas figuras do mundo diplomático que orientaram ideologicamente a campanha de Fernando Collor e sua plataforma de governo. De forma menos intensa, Roberto Campos, um dos defensores de uma agenda positiva com os Estados Unidos durante o período militar. Mais próximo do presidente estava José Guilherme Merquior, diplomata e intelectual público que o ajudou a transpor, para o campo político, suas ideias acerca do liberalismo social (Merquior 1987), trazido a público em discursos importantes de Collor, como o de posse e o de sua primeira participação na abertura da Assembleia Geral da ONU, em setembro de 1990. Nunca é demais ressaltarmos que esses dois exemplos ilustram posições muito mais liberais que aquelas defendidas pelo Itamaraty, em seu papel habitual de promoção do desenvolvimentismo.

Há, além dos "formadores ideológicos" do discurso de Collor, outras indicaçôes diplomáticas dignas de nota. Jório Dauster, durante a gestão econômica de Zélia Cardoso de Mello, foi a ponta de lança da renegociação da dívida externa junto aos credores norte-americanos. A Marcílio Marques Moreira, figura de fortes traços liberais (Moreira 2001), coube a continuidade dos trabalhos como embaixador brasileiro em Washington, interrompido somente em maio de 1991 para que o diplomata assumisse o "superministério" da Economia. Marcos Castrioto de Azambuja, por sua vez, defendeu incondicionalmente, à frente da Secretaria-Geral de Política Exterior do MRE, as noções de inserção competitiva e modernização via internacionalização (Azambuja 1991).

Além da inflexão liberal promovida nos escalóes mais altos da diplomacia, houve também uma tentativa de promover a desconcentração do poder político na 
chancelaria, por meio de reformas institucionais. Isso se deu, em grande medida, com o objetivo de evitar um secretário-geral particularmente forte, como havia sido o embaixador Flecha de Lima. É exatamente em torno dele, aliás, que gira a principal controvérsia suscitada por Collor em sua relação com a burocracia do serviço exterior: a famigerada "tripartição" da Secretaria-Geral do Itamaraty. O Decreto no 99.261, de 23 de maio de 1990, instituía três diferentes SecretariasGerais: a de Política Exterior, responsável por todos os Departamentos e suas respectivas Divisões, relacionados às áreas de política bilateral e multilateral, econômica, de promoção comercial e cooperação tecnológica, entre outras; a Secretaria-Geral Executiva, incumbida das questôes administrativas da Casa, sob a qual também estava o Instituto Rio Branco; e a Secretaria-Geral de Controle, à qual couberam todas as atribuições relacionadas à administração financeira, contabilidade e auditorias. Os três secretários-gerais, embaixadores Marcos Castrioto de Azambuja (SGPE), Eduardo Moreira Hosannah (SGE) e Sérgio de Queiroz Duarte (SGC), despachavam com o chanceler (Castro e Castro 2009, 121).

Os efeitos da tripartição foram imediatamente sentidos e condenados dentro do Ministério. Nas palavras de Celso Lafer, ao assumir a chancelaria, em maio de 1992, "o Itamarati [sic] estava, do ponto de vista interno, afetado por uma reforma administrativa, conduzida no primeiro momento do governo Collor por João Santana, que causou muita polêmica e muito desastre" (Lafer 1993, 274). Por outro lado, o próprio Secretário da Administração Federal do governo Collor, João Santana, alega que as mudanças institucionais inscreviam-se em um amplo "projeto de nova arquitetura organizacional para a administração pública federal", da qual o próprio presidente-eleito participou "nas etapas definitivas". Nesse contexto, a criação de três Secretarias-Gerais tinha como objetivo desconcentrar decisões políticas e administrativas das mãos de uma só figura, de forma a evitar "a personificação da administração pública, o que é inconveniente ao seu bom funcionamento" (Santana 2011).

Nesse contexto, existe um grande acordo a respeito de que uma das intenções de se subdividir a Secretaria-Geral era exatamente evitar um novo Paulo Tarso. Luiz Felipe Lampreia é categórico a esse respeito: para ele, o embaixador Marcos Coimbra havia criado "um esquema anti Paulo Tarso" (Lampreia 2010, 117). Rememorando o processo de mudança institucional, o ex-chanceler Rezek também subscreve a essa ideia, dizendo que foi concebida antes mesmo do início do governo, em função da "absorção de poder em sentido horizontal e vertical" da gestão daquele secretário-geral (Rezek 2011). A tripartição serviria, assim, para evitar uma concentração de poder que poderia reduzir o controle do presidente sobre a estrutura do ministério (Lampreia 2010).

Deve-se também levar em conta uma dimensão pessoal por trás das mudanças - não de Collor, mas de seu principal assessor diplomático, Marcos Coimbra. O presidente, aliás, teve a ajuda direta do embaixador Paulo Tarso na operacionalização do governo de transição, no chamado "bolo de noiva" do Itamaraty. Sem 
contar que o ex-secretário-geral do MRE, rigorosamente falando, pertencia ao grupo "ideológico" com que Collor simpatizava. A questão parecia estar, como sugere Rezek, no "núcleo familiar" do presidente, "que não morria de amores" por Paulo Tarso Flecha de Lima (Rezek 2011). Nesse sentido, o embaixador Rego Barros completa: "o Marcos Coimbra procurou mostrar ao Collor que - não, agora é outra coisa. Nós somos pessoas melhores e vamos deixar esse pessoal” (Barros 2011, 25).

Em todo caso, deve-se notar que poucas mudanças institucionais são tão unanimemente condenadas como foi a tripartição da Secretaria-Geral. Celso Amorim, em depoimento ao Centro de Pesquisa e Documentação de História Contemporânea do Brasil (CPDOC), sintetiza: "Aquilo foi um grande erro que depois se consertou. Aliás, ainda no governo Collor, porque o próprio ministro Resek [sic] viu que era impossível operar daquela forma" (Amorim 2003, 18). A impressão de Amorim é confirmada por Rezek, que acrescenta o fato de que havia atritos constantes entre os secretários-gerais, gerando problemas dentro da própria estrutura: "Não é uma boa coisa, três vice-ministros" (Rezek 2011). Por fim, o próprio ex-presidente faz o seu mea-culpa a respeito daquela mudança institucional: "Foi um erro. Não deveria ter feito isso. Eu fiz isso inspirado pelo Marcos Coimbra, que advogava exatamente essa questão de secretaria geral, era a super-secretaria. Mas isso criou muita confusão" (Collor 2011).

A publicação do Decreto no 99.578, de 10 de outubro de 1990, consolidou as mudanças administrativas iniciais da gestão de Francisco Rezek. Pela primeira vez, um decreto presidencial dispunha sobre a estrutura do MRE até o nível de Departamento, criando o Departamento de Meio Ambiente (DMA). Castro e Castro $(2009,125)$ anotam que essas transformações denotavam um esforço do Itamaraty em adaptar-se às transformações da agenda internacional, com a inclusão de novos assuntos, outrora secundários, como o meio ambiente ou a integração regional.

$\mathrm{Na}$ esteira das reformas institucionais, houve também uma alteração significativa nas regras da carreira, a chamada "expulsória". De acordo com a nova regra (já utilizada nas Forças Armadas), embaixadores ou ministros, após 15 anos na mesma categoria funcional, sofreriam uma espécie de aposentadoria compulsória, a partir da qual comporiam um "quadro especial" até a aposentadoria efetiva, aos 70 anos de idade. De acordo com Manuel Mendes, tratava-se de uma "forma esdrúxula de aposentadoria (...), um curioso sistema de administração de pessoal que não existe em nenhum outro serviço diplomático do mundo. Os diplomatas nesta situação não exercem função alguma, nem no Brasil nem no exterior, embora estejam em serviço ativo", passando a integrar o quadro especial, "que alguns chamam, com sarcástico realismo, de limbo" (Mendes 1995, 128-9).

Por se tratar de uma norma muito específica da carreira, a "expulsória" não é frequentemente trazida à tona no rol de mudanças institucionais, embora os diplomatas de carreira ressintam-se abertamente dela. Em depoimento ao CPDOC, o embaixador Luiz Felipe Lampreia faz menção a ela, tratando-se de uma "regra nova e terrível” (Lampreia 2010, 117). Sebastiāo do Rego Barros, em entrevista 
semelhante, considera a nova legislação " $[\mathrm{u}] \mathrm{ma}$ bobageira. E a coisa muito malfeita. Não é nada respeitável” (Barros 2011, 25).

Devemos dizer, brevemente, o que essas mudanças significaram no momento e nas circunstâncias em que elas foram implementadas. Pode-se observar, pelos depoimentos e pela argumentação expostos, que várias alterações foram realizadas sem muita certeza dos efeitos que causariam - redundando em equívocos - mas inspiradas, de alguma forma, pelo desejo de promover uma inflexão ideológica que alinhasse o Itamaraty às visóes de mundo advogadas pelo novo governo. Ao contrário do que reza a lenda, a diplomacia não foi marginalizada, mas reconfigurada - dentro dos limites de intervenção do presidente sobre uma estrutura burocrática bastante fechada. É como se o quarterback, além de cantar a jogada, pudesse escalar parte do time. Por outro lado, as mudanças propostas por Collor, porquanto limitadas, não causaram, nem de longe, um abalo sísmico no seio do serviço diplomático. E a política externa do período, como se quer sugerir, representou uma síntese entre o desejo de modernização, de abertura econômica, e a busca pela autonomia de inserção internacional, fio condutor do Itamaraty e uma de suas mais importantes tradições.

\section{Reflexões finais: que tipo de alinhamento?}

Resta-nos, portanto, perguntar que tipo de alinhamento emergiu durante o governo Collor. O período entre 1990 e 1992 foi reflexo direto de uma "tripla transformação" que acometeu o Estado brasileiro ao longo da década anterior, no tocante à produção de sua política exterior. Em primeiro lugar, caíram por terra as bases nacional-desenvolvimentistas que orientaram a inserção internacional do Brasil ao longo dos últimos governos militares. Segundo, o regime político sob o qual o País fora conduzido por mais de 20 anos, com fortes resquícios da Nova República adentro, também se reconfigurava, afirmando-se legitimamente democrático a partir da primeira eleição presidencial direta, em fins de 1989. Por fim, a mudança da ordem internacional - de uma estrutura bipolar aparentemente estável para uma não ordem com o ocaso da União Soviética e a implosão do Terceiro Mundo como bloco de poder - impôs a necessidade de reorientação internacional em especial aos países semiperiféricos, como parecia ser o caso do Brasil.

A fórmula do universalismo, aplicada de maneira absolutamente pragmática a partir do governo Geisel, parecia uma estratégia de grande alcance, bem-sucedida - que seus sucessores, parte ou não da corporação militar, fizeram questão de continuar. O problema, como se vê, é o progressivo distanciamento entre as estratégias previamente definidas e as necessidades objetivas do País, num contexto de mudanças profundas. Voltando aos termos de Allison (1969), o processo de aprendizagem organizacional, sendo usualmente mais lento que as transformações que ocorrem fora de sua estrutura - e incorporando-as de forma seletiva -, acaba 
gerando dissonâncias entre os componentes estrutural, societário e burocrático da política externa - ou, em outras palavras, uma "carência de foco" (Lafer 1993, 274).

Nesse contexto, as mudanças empreendidas pelo presidente Collor ao seu alcance imediato, ou seja, a inflexão promovida em favor de quadros mais liberais, bem como a reforma administrativa que reduziria o poder do secretário-geral, serviram para dar sentido a um tipo de orientação internacional que preenchia e conformava-se ao seu projeto neoliberal de modo mais amplo. Ou seja, não se pode dizer que Collor simplesmente embaralhou as cartas do Itamaraty na esperança de enfraquecer a corporação, alijando-a de forma derradeira do processo político. Havia, sim, um desejo de coerência, cujos resultados podem ser observados no decurso daquele governo.

Por isso mesmo, quando Batista $(1993,108)$ afirma que "[t]rata-se de uma política externa profundamente vinculada à visão de mundo e ao projeto nacional de Collor", isso não deve induzir a uma interpretação de que os quadros diplomáticos ficaram à margem do processo. Só seria cabível levar o raciocínio para esse lado se houvesse uma distância ontológica intransponível entre o serviço diplomático brasileiro e o Presidente da República - o que, como vimos, não se sustenta. Nesse sentido, não parece sensato alegar que o último conseguiu impor sua agenda externa em sua quase totalidade sobre o primeiro - havendo, pelo contrário, uma recomposição de forças (mesmo que paulatina) dentro do Ministério.

De toda forma, o tipo de orientação internacional que se configurou com a chegada de Collor ao poder não nos parece rumar para o extremo do pêndulo em que se conjuga o binômio americanismo/subordinação, como sustenta a maioria das análises (Batista 1993; Lima 1994; Hirst e Pinheiro 1995). Acompanhamos, aqui, a interpretação de Arbilla (2000), para quem a atualização da agenda externa brasileira, no despertar do novo governo, não foi acompanhada por uma mudança mais profunda dos quadros conceituais da política externa em termos paradigmáticos. Aquele tipo de alinhamento automático com os EUA, característico da Guerra Fria, que se mostrava até mesmo como um imperativo ideológico, não encontrava mais espaço no contexto da inserção internacional brasileira. Quer dizer, não se tratava de uma jogada possivel dentro do leque de alternativas que se apresentava.

Se houve algum tipo de inflexão, contudo, isso se deve não necessariamente a uma diplomacia presidencial intensa, mas a contradições dentro do próprio corpo diplomático. Collor soube jogar com elas, superando a inércia universalista, no sentido de flexionar sua política externa - devidamente amparado pelo serviço diplomático - rumo a uma inserção internacional mais positiva. O resultado, partindo de tudo que já tratamos, pode ser pensado como uma espécie de americanismo mitigado, abrandado pela própria dimensão burocrática, especialmente central no caso de nossa inserção exterior.

Nesse sentido, o governo Collor perseguiu uma síntese entre os paradigmas tradicionais, assegurando a busca histórica de nossa política externa pela autonomia 
e mantendo as linhas fundamentais daquilo que se entende como o "repertório permanente" da PEB (Mello e Silva 1995), em particular a diplomacia parlamentar/ multilateral e a não intervenção em assuntos domésticos de outras nações. Coloca-se em evidência, assim, uma estratégia em que planos regional e global complementam-se, tomando como base a abertura econômica e a afirmação da democracia como fonte de legitimação e, ao mesmo tempo, de projeção de poder. Destarte, o investimento no Mercosul como forma de projetar economicamente a região, o alinhamento condicionado ao Primeiro Mundo (em particular aos Estados Unidos) e a rejeição completa do projeto nuclear advindo do regime anterior são compreendidos a partir deste novo marco conceitual que busca tornar inteligível esse período curto, embora fundamental, da política externa brasileira.

\section{Referências bibliográficas}

\section{Fontes primárias:}

AMORIM, Celso Luiz Nunes. Celso Amorim (depoimento, 1997). Rio de Janeiro, CPDOC, 2003. BARROS, Sebastiāo do Rego. Sebastiāo do Rego Barros II (depoimento, 2009). Rio de Janeiro: CPDOC, 2011.

COLLOR DE MELLO, Fernando. Entrevista concedida ao autor. Brasília, 13 de junho de 2011. FLECHA DE LIMA, Paulo Tarso. Entrevista concedida ao autor. Brasília, 19 de maio de 2011. LAFER, Celso. "Entrevista com Celso Lafer". Estudos Históricos, vol. 6, no. 12, 1993.

LAMPREIA, Luiz Felipe. Luiz Felipe Lampreia (depoimento, 2008). Rio de Janeiro, CPDOC, 2010. REZEK, Francisco. Entrevista concedida ao autor. São Paulo, 04 de maio de 2011.

SANTANA, João. Entrevista concedida ao autor. São Paulo, 04 de maio de 2011.

\section{Fontes secundárias:}

ALLISON, Graham T. "Conceptual Models and the Cuban Missile Crisis". The American Political Science Review, vol. LXIII, no. 3, 1969.

ARBILLA, José María. “Arranjos Institucionais e Mudança Conceitual nas Políticas Externas Argentina e Brasileira (1989-1994)”. Contexto Internacional, vol. 22, no. 2, 2000.

AZAMBUJA, Marcos Castrioto de. “A Política Externa do Governo Collor". São Paulo: Instituto de Estudos Avançados, 1991.

BATISTA, Paulo Nogueira. “A Política Externa de Collor: modernização ou retrocesso?”. Política Externa, vol. 1, no. 4, 1993.

CASON, Jeffrey; POWER, Timothy. "Presidentialization, Pluralization, and the Rollback of Itamaraty”. International Political Science Review, vol. 30, no. 2, 2009. 
CASTRO, Flávio Mendes de Oliveira e CASTRO, Francisco Mendes de Oliveira. 1808-2008 Dois Séculos de História do Itamaraty. Volume 2 (1979-2008). Brasília: FUNAG, 2009.

CHEIBUB, Zairo. "Diplomacia e Construção Institucional: o Itamaraty em perspectiva histórica”. Dados, vol. 28, no. 1, 1985.

DANESE, Sérgio França. Diplomacia Presidencial. Rio de Janeiro: Topbooks, 1999.

FARIA, Carlos Aurélio Pimenta de. "Opinião Pública e Política Externa: insulamento, politização e reforma na produção da política exterior do Brasil”. Revista Brasileira de Política Internacional, vol. 51, no. 2, 2008.

FERREIRA, Tulio Sérgio Henriques. O Universalismo e seus descontentes: a política exterior do Brasil no governo Figueiredo (de 1979 a 1985). Curitiba: Juruá, 2009.

FLECHA DE LIMA, Paulo Tarso. "Modernização e obstáculos para a Internacionalização da Economia Brasileira”. Revista Brasileira de Política Internacional, ano XXXI, no. 123-4, 1988.

HIRST, Monica e PINHEIRO, Letícia. "A Política Externa do Brasil em dois tempos”. Revista Brasileira de Politica Internacional, vol. 38, no. 1, 1995.

LAFER, Celso. "O Legado Diplomático da Viagem Presidencial de Tancredo Neves". Contexto Internacional, vol. 1, no. 2, 1985.

LIMA, Maria Regina Soares de. "Ejes Analíticos y Conflicto de Paradigmas en la Política Exterior Brasileña”. América Latina/Internacional, vol. 1, no. 2, 1994.

LIMA, Maria Regina Soares de; SANTOS, Fabiano. "O Congresso e a Política de Comércio Exterior". Lua Nova, no. 52, 2001.

MELLO, Flávia de Campos. "Regionalismo e Inserção Internacional: continuidade e transformação da política externa brasileira nos anos 90". Tese de doutorado, FFLCH/USP, 2000.

MELLO E SILVA, Alexandra de. "O Brasil no Continente e no Mundo: atores e imagens na política externa brasileira contemporânea”. Estudos Históricos, vo. 8, no. 15, 1995.

MENDES, Manuel. O Cerrado de Casaca. Brasília: Thesaurus, 1995.

MERQUIOR, José Guilherme. "Brazil's New Republic: The Social-Liberal Path”. Bulletin of Latin American Review, vol. 6, no. 2, 1987.

MOREIRA, Marcílio Marques. Diplomacia, Política e Finanças. Rio de Janeiro: Objetiva, 2001.

OLIVEIRA, Amâncio Jorge de; ONUKI, Janina. "Eleições, Partidos Políticos e Política Externa no Brasil". Revista Política Hoje, vol. 19, no. 1, 2010.

RICUPERO, Rubens. Diário de Bordo: a viagem presidencial de Tancredo. São Paulo: Imprensa Oficial, 2009.

SANCHEZ-BADIN, Michelle Ratton; FRANÇA, Cássio Luiz de. "A inserção internacional do poder executivo federal brasileiro". Análises e Propostas. São Paulo: Friedrich-Ebert-Stiftung, 2010.

SILVA, Vera Alice Cardoso; DELGADO, Lucília de Almeida Neves. Tancredo Neves: a trajetória de um liberal. Belo Horizonte/Petrópolis: UFMG/Vozes, 1985.

VELASCO e CRUZ, Sebastião Carlos. Globalização, Democracia e Ordem Internacional. Campinas/São Paulo: Ed. Unicamp/ Ed. UNESP, 2004. 
VELLOSO, João Paulo dos Reis. "Alternativas do Brasil em Face da Iniciativa Bush". In: VELLOSO, João Paulo dos Reis (org.). O Brasil e o Plano Bush: oportunidades e riscos numa integração das Américas. São Paulo: Nobel, 1991.

VIZENTINI, Paulo G. Fagundes. "A Política Externa Brasileira em Transição: do desenvolvimentismo ao neoliberalismo". In: MARTINS, Estevão Chaves de Rezende (org.). Relações Internacionais: visóes do Brasil e da América Latina. Brasília: IBRI, 2003.

Recebido em 30 de setembro de 2011 Aprovado em 12 de janeiro de 2012

\section{Resumo}

O objetivo deste trabalho é investigar o papel do Ministério das Relações Exteriores na política externa do governo Collor, relação comumente observada como frágil. Argumenta-se que, em vez de marginalizar o Itamaraty, o presidente reconfigurou a chancelaria, tanto em termos de seus decisores principais quanto em termos administrativos. A consequência foi o estabelecimento de uma política externa de feições mais liberais - um americanismo mitigado - em sintonia com os objetivos tradicionais das relações exteriores do Brasil.

Palavras-chave: Fernando Collor; Itamaraty; política externa brasileira.

\section{Abstract}

This work looks at the role of the Foreign Ministry in Fernando Collor's foreign policy, which is usually considered feeble. We argue that, instead of putting Itamaraty on the sidelines, the president reconfigured the ministry, both in terms of its key decision-makers and in administrative terms. The outcome was the establishment of a more liberal foreign policy - a mitigated Americanism - in tune with the traditional goals of Brazil's foreign relations.

Keywords: Fernando Collor; Itamaraty; Brazilian foreign policy. 